\title{
El agua en la imagen literaria del Madrid de Lope de $\operatorname{Vega}^{1}$
}

\section{Water in Lope de Vega's Literary Image of Madrid}

\author{
EVA GUTIÉRREZ PRADA \\ Universidad Nacional de Educación a Distancia \\ egutierre126@alumno.uned.es
}

\begin{abstract}
Resumen: Lope de Vega recreó en su obra muchas escenas en las que el agua era un elemento indispensable en la construcción de la imagen literaria de Madrid. El poeta recurre a lo beneficioso de las aguas, río o fuentes, como argumento de grandeza de la ciudad dentro de la norma corográfica de la época. En su poética, por tanto, subyace el ideal de modelo urbano clásico aplicado a una villa que aspiraba a ser asiento estable de la Corte. Además, con la introducción de estos topoi historiográficos, contribuyó en la difusión de las laudes de Madrid a través del teatro.
\end{abstract}

Palabras claves: Lope de Vega, agua, iconografía urbana, Madrid, Manzanares.

Abstract: In his work, Lope de Vega recreated scenes in which water becomes an indispensable element in the construction of Madrid's literary image. He uses the benefits of water, rivers and fountains as argument in defense of the town within the chorographic standard of the Modern Age. The underlying theme of his poetry is thus the classic urban idyllic model applied to a town that aspired to be the steady seat of the Court. With the introduction of these historiographic topoi, Lope de Vega contributed to the spread of the laudes of Madrid through theatre.

Keywords: Lope de Vega, water, urban iconography, Madrid, Manzanares.

${ }^{1}$ El presente trabajo es parte de una tesis doctoral en curso sobre la ciudad en Lope de Vega del programa de
doctorado en Historia e Historia del Arte y Territorio de la Universidad Nacional de Educación a Distancia. Recibido: 6 de junio de 2017; aceptado: 5 de diciembre de 2017; publicado: 27 de marzo de 2018. Revista Historia Autónoma, 12 (2018), pp. 79-97. e-ISSN: 2254-8726; DOI: https://doi.org/10.15366/rha2018.12.004. 
Las bondades del agua, junto con las del viento, se incorporaron a las laudes hispanas y las historias de ciudades ${ }^{2}$ durante los siglos XVI y XVII a partir de la ciudad ideal ${ }^{3}$. En el caso concreto de la villa de Madrid $^{4}$, este elemento fue muy elogiado por cronistas, escritores y viajeros, y muy recurrente en la producción lopedeveguesca asociado al mito fundacional, o en la recreación de la villa como locus amoenus, o con sus cualidades taumatúrgicas en la curación de varias enfermedades. A las aguas subterráneas, arroyos y fuentes de Madrid, escritores y cronistas dedicaron páginas de alabanzas, pues ennoblecía la villa y la hacía merecedora de acoger a la Corte de manera estable ${ }^{5}$. No estamos diciendo que el agua fuera el motivo del traslado de la Corte de Toledo a Madrid ${ }^{6}$. Actualmente se admite que la elección de Madrid por parte de Felipe II dependiera de la puesta en marcha de un programa cultural y político en una villa cuya "discreción histórica", con respecto a otras ciudades, permitía la experimentación de la concepción felípica. Ahora bien, los argumentos a favor del clima y sitio saludable de Madrid, que sin duda se instrumentalizaron políticamente en función de las teorías aeristas para evitar el traslado de la Corte, y el calado fuera del ámbito puramente político demuestran su importancia como elemento retórico en la construcción de la imagen literaria de la villa.

\footnotetext{
${ }_{2}^{2}$ Sobre las historias de las ciudades, véase Quesada, Santiago, La idea de ciudad en la cultura hispana de la edad moderna, Barcelona, Publicacions de la Universitat de Barcelona, 1992.

${ }^{3}$ Sobre la ciudad ideal, Pavia, Rosario, L'idea di città. Teorie urbanistiche della città tradizionale, Milán, Electa, 1987; Kruft, Hanno Walter y Mauro Tosti Croce, Storia delle teorie architettoniche da Vitruvio al Settecento, Bari, Laterza, 1988; Kruft, Hanno Walter, Le città utopiche: le città ideali dal XV al XVIII secolo fra utopia e realtà, Bari, Laterza, 1990.

${ }^{4}$ Sobre Madrid y el ideal urbano, véase Ringrose, David et al., Madrid, historia de una capital, Madrid, Alianza, 1994; Esquivias Blasco, Beatriz, "Madrid, utopía y realidad de una ciudad capital”, en Madrid. Revista de arte, geografia e historia, 1 (1998), pp. 47-72; González de la Fuente, Dolores, "Felípica, capital de la monarquía (propuestas de Pérez de Herrera para Madrid)", en Espacio, tiempo y forma. Serie VII: Historia del arte, 15 (2002), pp. 27-47; Cavillac, Michel, "El Madrid utópico (1597-1600) de Cristóbal Pérez de Herrera", en Bulletin hispanique, vol. 104, 2 (2002), pp. 627-644. DOI: https://doi.org/10.3406/hispa.2002.5126.

${ }^{5}$ Sobre las bondades del cielo y de las aguas como motivos del traslado junto con la cercanía de los Sitios Reales: Alvar Ezquerra, Alfredo, Felipe II, la corte y Madrid en 1561, Madrid, Consejo Superior de Investigaciones Científicas, 1985; Alvar Ezquerra, Alfredo, "Nacimiento y consolidación de Madrid-Corte: 1561-1606", en Alvar Ezquerra, Alfredo (coord.), Visión histórica de Madrid (siglos XVI al XX), Madrid, Real Sociedad Económica Matritense de Amigos del País, 1991, pp. 9-34; Fernández Álvarez, Manuel, "El establecimiento de la capitalidad de España en Madrid", en Madrid en el siglo XVI, Madrid, Consejo Superior de Investigaciones Científicas, 1962, Tomo I, pp. 1-24; Fernández Álvarez, Manuel y José Antonio Maravall, El Madrid de Felipe II (En torno a una teoría sobre la capitalidad), discurso de ingreso en la Real Academia de la Historia, Madrid, 1987, pp. 9-42; Pérez Bustamante, Ciriaco, La capitalidad de Madrid, Madrid, Sección de cultura, 1963; Esquivias Blasco, Beatriz, "El cielo (y el suelo) de Madrid. La incidencia del clima en la capitalidad", en Felipe II y las artes: Actas del Congreso Internacional 9-12 diciembre 1998, Madrid, Universidad Complutense de Madrid, 2000, pp. 371-382. Diferentes son las hipótesis que ha barajado la historiografía en cuanto a la elección de Madrid. Sobre las ventajas e inconvenientes del establecimiento de la Corte, a saber, la situación central, la seguridad, el vacío de poderes en la villa y los motivos simbólicos, véase además Alvar Ezquerra, Alfredo, El nacimiento de una capital europea. Madrid entre 1561 y 1606, Madrid, Turner-Ayuntamiento de Madrid, 1989; Alvar Ezquerra, Alfredo, "Madrid: dos ciudades en una", en Bravo Lozano, Jesús (coord.), Congreso Internacional Espacios de poder: Cortes, ciudades y villas (ss. XVI-XVIII). Vol. II, Madrid, Universidad Autónoma, 2002, pp. 335-344; Montoliú Camps, Pedro, Madrid. Villa y Corte, historia de una ciudad, Madrid, Sílex, 1996; Del Río Barredo, María José, Madrid, urbs regia: la capital ceremonial de la monarquía católica, Madrid, Marcial Pons, 2000; Stewart, Jules, Madrid: the history, Londres y Nueva York, IB Tauris, 2012.

${ }^{6}$ Sobre el problemático abastecimiento de aguas en Toledo como uno de los motivos del traslado de la corte a Madrid, Alvar Ezquerra, Alfredo, Felipe II, la corte...op. cit., pp. 4-11; Jufre García, Xavier, El artificio de Juanelo Turriano para elevar agua al Alcázar de Toledo: modelo con escaleras de Valturio, Lleida, Editorial Milenio, 2008.

${ }^{7}$ Esquivias Blasco, Beatriz, "Madrid, utopía...” op. cit., p. 50.
} 
En las páginas siguientes nos aproximaremos a la obra de Lope de Vega analizando la importancia de este elemento clásico en la construcción del mito y la idealidad de la ciudad.

\section{1. "Madrid, armada sobre agua"}

Siguiendo a los autores clásicos, los escritores del siglo XVI alabaron las bondades del clima ideal de la ciudad. Según Aristóteles, la salud de los ciudadanos en la ciudad ideal dependía de la buena situación del enclave, de la exposición a los vientos y de la buena calidad de las aguas porque "aquellas cosas, de que más de ordinario para la conservación de los cuerpos nos servimos, importan más para la conservación de la salud. La facultad, pues, de las aguas y los vientos parece ser deste jaez"8.

Vitruvio también elegía un "parage sano" para la construcción de la ciudad dependiendo de su situación con relación al cielo que “debe ser fértil y abundante por sí mismo, [que] tenga ríos y puertos capaces de suministrarla". El arquitecto, pues, debe asegurarse de "la comodidad del sitio donde debe formar su Población por medio de un conocimiento exacto de la bondad de su ambiente, de la fertilidad del terreno y de la facilidad de los caminos, ríos y puertos de mar" ${ }^{10}$. Asimismo Alberti, heredero de la filosofía griega, sostenía que la ciudad debía situarse en un lugar fértil, que fuera capaz de explotar el propio territorio circundante, y para ello lo más apropiado era fundar la ciudad en el centro de su territorio, en un llanura montañosa (meseta) cerca de la costa, o en su defecto en las proximidades de un río, lo cual permitiría el abastecimiento y trasporte de materiales. Aconsejaba, pues, la abundancia "de fuentes, [que] haya río, lagos, y esté patente la oportunidad de la mar [...]"11. Desde Italia ${ }^{12}$ también Botero resaltaría, entre las características de la ciudad-capital, la "comodidad del agua"13, teoría que confería solidez a la fama de las aguas de Madrid. El tópico era anterior, en cualquier caso, al

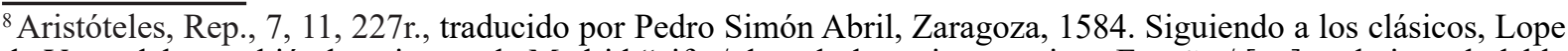
de Vega alaba también los vientos de Madrid "cifra/ de todo lo mejor que tiene España;/ [...] y el aire saludable [...] / es el más importante cortesano", en de Vega, Lope, El Acero de Madrid, Madrid, Castalia, 2000, pp. 106107. Hemos adaptado en todos los casos la ortografía al uso moderno respetando las contracciones típicas de la época. Para la datación de las obras, excepto donde se especifique, seguimos a Griswold Morley, Sylvanus y Courtney Bruerton, Cronología de las comedias de Lope de Vega, Madrid, Gredos, 1968 (la primera edición, en inglés, es de 1940).

${ }^{9}$ Vitruvio, de Arch., 3, 1, 53, traducido por Joseph Castañeda, Madrid, Imprenta de Gabriel Ramírez, 1761.

${ }^{10}$ Ibídem, 3, 4, 60.

${ }^{11}$ Alberti, León Batista, Los diez libros de arquitectura, Madrid, Joseph Franganillo, 1797, vol. I, lib. IV, cap. II, p. 161.

${ }^{12}$ Piénsese en la ciudad ideal de Sforzinda atravesada por el río y rodeada de canales para garantizar el abastecimiento y el transporte, o Venecia, toda ella rodeada de agua, consecuenciade su fuerza y estabilidad política. Véase al respecto Filarete, Antonio Averlino, Trattato di architettura, Milán, Il Polifilo, 1972; y Cataneo, Pietro, I quattro libri di architettura, Venecia, Aldus, 1554.

${ }^{13}$ Botero, Juan, Razón de Estado con tres Libros de las grandezas de las Ciudades... traducido de italiano en castellano por Antonio Herrera, Burgos, 1605, citado en Checa Cremades, Fernando, "Felipe II y la ordenación del territorio en torno a la Corte", en Archivo español de arte, t. 58, 232 (1985), p. 393.
} 
traslado de la Corte ${ }^{14}$. Desde el humanismo de la escuela de Anglería en Madrid $^{15}$, o los dos emblemas que Juan Hurtado de Mendoza incluía en su obra ${ }^{16}$, retomados después por Juan López de Hoyos ${ }^{17}$, las alabanzas de la fertilidad del suelo y el agua buena y abundante de la villa se fueron repitiendo en diferentes autores como Jerónimo Münzer, Marineo Sículo, Pedro de Medina o Ambrosio de Morales; "la sanidad e lindos aires" de Fernández de Oviedo ${ }^{18}$, la importancia de "la limpieza y pureza de las aguas" para Bovadilla19o las "buenas aguas, admirable costelación, aires admirables" de Cabrera de Córdoba ${ }^{20}$, eran argumentos a favor del asiento estable de la Corte en Madrid"1. Gil González Dávila define Madrid como "sitio deleitoso y abundante por la fertilidad de su terreno, y felices aspectos de su cielo, mostrándose en esta tierra la naturaleza tan liberal y fecunda"22.

La importancia del agua se filtró en su mito fundacional y se fue asentado en la "norma corográfica" ${ }^{23}$ de la villa. Lope de Vega reproduce en los siguientes versos de 1630 la ya famosa leyenda — a partir de la Mantua virgiliana y las Tablas de Ptolomeo con los grados de Mantua, Toletum y Complutum-, del príncipe griego Ocnor. El hijo de Manto fundó en la Carpetania

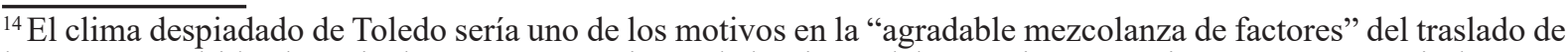
la Corte a Madrid. Alvar cita hasta tres procesiones de la Virgen del Sagrario en rogativa por agua a partir de 1561, en Alvar Ezquerra, Alfredo, "La elección de la corte. La política en los siglos XVI y XVII", en Fernández García, Antonio (coord.), Madrid, de la Prehistoria a la Comunidad Autónoma, Madrid, Consejería de Educación, 2008, pp. 150 y 145-146 respectivamente. Según Asín, los problemas hídricos de Madrid habían provocado el traslado a Valladolid, pero ha sido desmentido por Alvar Ezquerra, Alfredo, Felipe II, la Corte... op. cit., p. 52; y Fernández Álvarez, Manuel y José Antonio Maravall, El Madrid... op. cit., p. 17. Madrid contaba con un buen abastecimiento hasta la llegada de la Corte, pero ante el impacto a partir de 1606 se realizaron nuevos viajes, véase Pérez Boldo, Amparo y Fernando Arroyo Ilera, "Madrid: agua, Corte y Capital en los siglos XVI al XVIII", en Boletín de la Real Sociedad Geográfica, 139-140 (2003-2004), p. 191.

${ }^{15}$ Alvar Ezquerra, Alfredo, La Villa de Madrid vista por los extranjeros en la alta Edad Moderna, Madrid, Artes Gráficas Municipales, 1990, pp. 9-10.

${ }^{16}$ Hurtado de Mendoza, Juan, Buen plazer trobado en treze discãtes de quarta rima Castellana segun imitacion de trobas Francesas compuesto por don Juan Hurtado de Mendoça, Alcalá, 1550. Sobre los escudos de Madrid, véase Carrascosa Megía, Joaquín, Historia de los escudos de la Villa de Madrid, Madrid, Giner Méndez, 1981; y del Riego Vivar, José Antonio, "Símbolos heráldicos de Madrid", en Ávila Seoane, Nicolás (coord.), Paseo documental por el Madrid de antaño, Madrid, Universidad Complutense de Madrid, 2015, pp. 375-397.

${ }^{17}$ López de Hoyos, Juan, Real apparato, y sumptuoso recebimiento con que Madrid rescibio a la serenessima Reyna D. Ana de Austria, Madrid, 1572.

${ }^{18}$ Citados como argumentos a favor del asiento estable de la Corte en Madrid en Fernández Álvarez, Manuel y José Antonio Maravall, El Madrid...op. cit., pp. 17-18.

${ }^{19}$ Castillo de Bovadilla, Jerónimo, Política para Corregidores y Señores de Vasallos, en tiempo de paz y de guerra ... vol. 2, lib. III, Madrid, Instituto de Estudios de Administración Local, 1978, cap. VI, p. 87.

${ }^{20}$ Cabrera de Córdoba, Luis et al., Historia de Felipe II, Salamanca, Consejería de Educación y Cultura, 1998, p. 218.

${ }^{21}$ Sobre la incidencia del clima en la elección de Madrid como Corte estable, véase Esquivias Blasco, Beatriz, "Madrid, utopía..." op . cit., p. 65; Esquivias Blasco, Beatriz, "El cielo...” op. cit., pp. 371-382. Según Pérez Boldó y Arroyo Ilera, no se trataría tanto de la elección de una ciudad, sino más bien de un espacio más amplio en el que influyen los "factores de situación" o las características de una zona, que son precisamente en las que insisten los cronistas de la época, a saber, abundancia de aguas, buenos aires, excelentes bosques, el centro peninsular como corazón del Imperio. Pérez Boldó, Amparo y Fernando Arroyo Ilera, "Madrid: agua..." op. cit. Este espacio se puede identificar con la inmensa "república-palacio" del Rey, en Alvar Ezquerra, Alfredo, El nacimiento... op. cit., p. 191.

${ }_{22}^{22}$ González Dávila, Gil, Teatro de las grandezas de la Villa de Madrid...., Madrid, Tomás Iunti, 1623, cap. I, fol. 4.

${ }^{23}$ Kagan, Richard, "Clío y la Corona: escribir historia en la España de los Austrias", en Kagan, Richard y Geoffrey Parker (coords.), España, Europa y el Mundo Atlántico. Homenaje a John H. Elliot, Madrid, Marcial Pons, 2001, p. 135.
} 
una ciudad en un lugar muy fértil con un gran número de arroyos y la encomendó a la diosa Metragirta $^{24}$ :

\author{
Cuando el hijo famoso de Tiberio, \\ gran Rey de los Latinos, \\ después de discurrir Reinos extraños, \\ fundó a Madrid, primero que el Imperio \\ del mundo sujetase el cuello a Roma \\ casi doscientos años, \\ de Manto el nombre toma \\ de Mantua, y por Viserio \\ Viseria del Dragón, blasón que tuvo ${ }^{25}$.
}

Este tipo de leyendas ${ }^{26}$ en las que la fundación de la ciudad está asociada a un lugar fértil, con un buen abastecimiento de agua, era muy frecuente en las historias y crónicas de la ciudad, lo cual demuestra el papel relevante del agua en el enclave urbano. Es interesante destacar también, dentro de este proceso de construcción y asimilación cultural colectiva, la importancia del origen etimológico de los topónimos: Magerit significa "venas o conductos de agua"27, pues según las Relaciones Topográficas de Felipe II "la terra toda está foradada de venas y de cavas por donde van y pasan las aguas"28, idea que responde a una "concepción subterránea del ciclo hidrológico" del agua ${ }^{29}$. Por eso Fernández de Oviedo en 1555 explicaba el antiguo dicho "Madrid la Osaria, cercada de fuego, armada sobre agua"30.

El mito, recogido en diferentes autores y obras, penetró también en el teatro y en la iconografía de la fiesta pública, retomando elementos de la Antigüedad clásica según la

\footnotetext{
${ }^{24}$ Véase González Dávila, Gil, Teatro de las... op. cit., cap. I, fol. 4; de la Quintana, Jerónimo, A la muy antigua, noble y coronada villa de Madrid. Historia de su antigüedad, nobleza y grandeza, Madrid, Imprenta del Reino, 1629, fol. 4 y ss. (ed. facsímil, 2 vols., Madrid, 1980); Núñez de Castro, Alonso, Libro histórico político Solo Madrid es Corte y el Cortesano de Madrid, Madrid, Antonio Riero y Texada, 1669, p. 4. Las referencias a la etimología de Mantua Carpetana aparecen ya en Marineo Sículo (1530) o Gaspar de Barreiros (1542) y, según Alvar Ezquerra, derivan del humanismo de Anglería. Alvar Ezquerra, Alfredo, La Villa ... op. cit., pp. 8-13.

${ }^{25}$ De Vega, Lope, El laurel de Apolo, en Colección de obras sueltas assi en proa como en verso, Madrid, 1776, vol. I, silva V, pp. 87-88.

${ }^{26}$ Véase el estudio Delage, Agnès, "Mantua carpetana. La construction d'une légende toponymique de la fondation de Madrid", en Delpech, François (coord.), L'imaginaire du territoire en Espagne et au Portugal (XVIe-XVIIe siècles), Madrid, Casa de Velázquez, 2008, pp. 61-78. Sobre la "(re)invención” del pasado intercalando en la historia mitos, ritos, eventos, leyendas, milagros, etc. con la intención de justificar el presente y construir una identidad colectiva nacional y/o local, véase Kagan, Richard, "Clío y la Corona..." op. cit.; Kagan, Richard, Los cronistas y la corona. La política de la historia en España en las Edades Media y Moderna, Madrid, Marcial Pons, 2010; Sesma Muñoz, José Ángel, "La creación de la memoria histórica, una selección interesada del pasado", en de la Iglesia Duarte, José Ignacio et al. (coords.), Memoria, mito y realidad en la Historia Medieval. XII Semana de estudios medievales, Logroño, Instituto de Estudios Riojanos, 2003, pp. 13-32.

${ }^{27}$ Cfr. Oliver Asín, Jaime, Historia del nombre “Madrid”, Madrid, Consejo Superior de Investigaciones Científicas, 1958 p. 102. La leyenda sería anterior a 1555 cuando Juan Hurtado de Mendoza introduce en su obra el escudo de Madrid y la inscripción.

${ }^{28}$ Citado en Arroyo Ilera, Fernando, "La imagen del agua: ideas y nociones hidrográficas en las relaciones topográficas de Felipe II", en Madrid, revista de arte, geografia e historia, 1 (1998), p. 158.

${ }^{29}$ Arroyo Ilera, Fernando, Agua, paisaje y sociedad en el siglo XVI según las Relaciones Topográficas de Felipe II, Madrid, Ediciones del Umbral, 1998.

${ }^{30}$ Citado por Mesonero Romanos, Ramón, Antiguo Madrid. Paseos histórico-anecdóticos por las calles y casas de esta villa, Madrid, 1861, fol. XXVI, nota 2. Para el origen de este adagio y Ruy González Clavijo, véase de la Quintana, Jerónimo, A la muy antigua... op. cit., lib. I, cap. XXIIII, fol. 31r.
} 
historiografía italiana. La figura de Mantua aparece en la entrada triunfal de Margarita de Austria en Madrid en 1599, o posteriormente en la de Isabel de Borbón en 1615 — hechos que Jerónimo de la Quintana ofrece como prueba de la veracidad del mito-, y se construyeron arcos triunfales con las figuras de Ocnor Bionor entregando las llaves de la ciudad y la oferta de la corona por parte de Manto ${ }^{31}$. El mismo mito y significados etimológicos aparecen también en Lope de Vega en la comedia San Isidro, labrador de Madrid ${ }^{32}$ (de 1604-1606 con la corte en Valladolid). También Texeira utilizó el mito como título del mapa que hiciera para Felipe IV en 1656 (Mantua Carpetatorum sive Matritum Urbs Regia).

\section{2. "Riberas del estrecho Manzanares"}

En toda corografía se daba noticia del nacimiento del río y etimología del nombre: "el cristal, que le dieron las montañas,/ de donde toma el nombre"33 el Manzanares, pues indivisible es la imagen de la ciudad y el río como atributo tanto económico, como simbólico. Así lo demuestra la vista comunicéntrica ${ }^{34}$ que Felipe II encargó a Wyngaerde ${ }^{35}$ [fig. 1]. Aquí Wyngaerde retrata el antiguo puente de Segovia que fue sustituido por el nuevo, encargado primero a Gaspar de Vega y a su muerte a Juan de Herrera en 1584, y que podemos ver ya en la Vista del Alcázar de Madrid de Félix Castello de 1630-1640 [fig. 2] y también en el mapa de Texeira.

Figura 1: Vista de Madrid, de Anton Van Den Wyngaerde (1562).

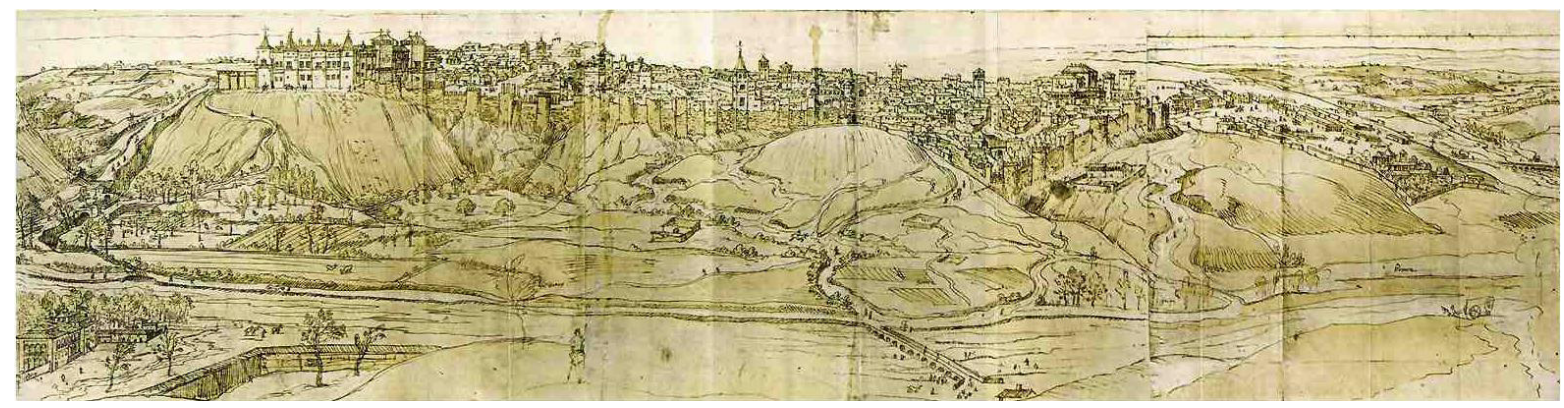

Fuente: Biblioteca Nacional de Austria.

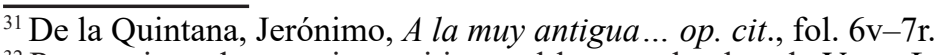

${ }^{32}$ Por motivos de espacio remitimos al lector a la obra de Vega, Lope, San Isidro, labrador de Madrid, acto III, versos 677-682.

${ }^{33}$ De Vega, Lope, El laurel de Apolo...op. cit., pp. 89-91. Cfr. González Dávila, Gil, Teatro de las...op. cit., lib. I, fol. 7.

${ }^{34}$ Para las vistas corográficas y las vistas comunicéntricas, véase Kagan, Richard y Fernando Marías, Imágenes urbanas del mundo hispánico, 1493-1780, Madrid, El Viso, 1998.

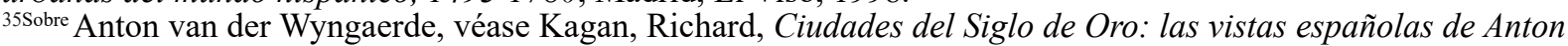
van den Wyngaerde, Madrid, El Viso, 1987; Kagan, Richard, "Felipe II y el arte de la representación de paisajes urbanos", en Anuario del Instituto de Estudios histórico sociales, 24 (2009), pp. 95-110.
} 
Más allá de su simbología, a diferencia del Tajo o el Guadalquivir, el Manzanares era de menor importancia:

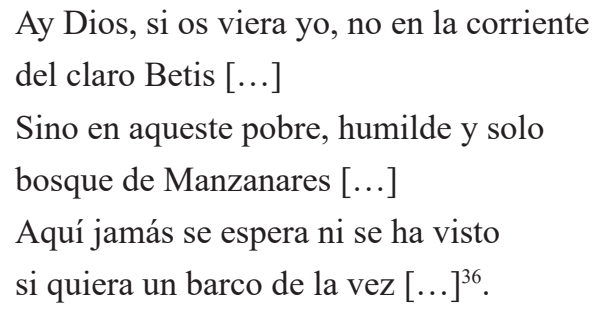

Ante las deficiencias de la villa por no tener un río caudaloso y navegable, se presentaron soluciones que no se alejaran demasiado del modelo ideal. En las últimas décadas del siglo XVI Felipe II pone en marcha, dentro de su proyecto de ordenación del territorio, un plan de navegabilidad de los ríos hispánicos ${ }^{37}$. En 1582 encarga al ingeniero italiano Antonelli hacer navegable el Manzanares con el trasvase de Jarama y Tajo con la intención de unir la villa con el puerto hispánico de Lisboa. El plan prosiguió durante el reinado de Felipe III. Pérez de Herrera entre las cinco soluciones para el ornato de la ciudad, y así convertir la villa en "Corte perpetua", plantea como quinta propuesta "acrecentarle el río que tiene, con que será tan populosa y de tanta grandeza"38. A pesar de los esfuerzos, en ningún caso se consiguió hacer del Manzanares un río navegable ${ }^{39}$ ni se vieron barcos sobre él, como lamenta Lope en los versos anteriores de 1621.

A toda esa serie de ingenieros y arquitectos con sus propuestas corresponde una serie de escritores, cronistas y arbitristas que, proponiendo soluciones de mejora como Pérez de Herrera, inculcan en el imaginario colectivo una determinada imagen ideal en contraste con la realidad. En las Relaciones, a diferencia del Tajo caudaloso todo el año, el Manzanares tenía agua suficiente en invierno y de uno a cuatro meses de sequía en verano ${ }^{40}$ : “¡Ay de ti, Manzanares,

\footnotetext{
${ }^{36}$ De Vega, Lope, “La Filomena, epístola IV a Don Diego Félix Quijada y Riquelme”, en Rosell, Cayetano (ed.), Colección escogida de obras no dramáticas de Frey Lope Félix de Vega Carpio, Madrid, Rivadeneyra, 1856, p. 420, citado en Simón Díaz, José, Guía literaria de Madrid: De murallas adentro, Madrid, Instituto de Estudios Madrileños, 1993, p. 231.

${ }^{37}$ Para el plan de política hidráulica que Felipe II puso en marcha en 1560 en Aranjuez, véase Segura, Cristina y Juan Carlos de Miguel, "La política hidráulica de Felipe II en el heredamiento de Aranjuez", en Madrid, revista de arte, geografia e historia, 1 (1998), pp.195-218.

${ }^{38}$ Pérez de Herrera, Cristóbal, Discurso a la Catolica y Real Magestad del Rey D. Felipe nuestro Señor, en que se le suplica, que considerando las muchas calidades y grandezas de la villa de Madrid, se sirva de ver si conuendria honrarla, y adornarla de muralla, y otras cosas que se proponen, con que mereciese ser Corte perpetua, y assistencia de su gran Monarchia, sl., fol. 3r.

${ }^{39}$ Para el proyecto de Juan Bautista Antonelli de hacer navegable el Tajo con los afluentes Jarama-Manzanares en 1581, véase Rivera Blanco, Javier José, Juan Bautista de Toledo y Felipe II. La implantación del clasicismo en España, Valladolid, Universidad de Valladolid, 1982; Checa Cremades, Fernando, "Felipe II y la ordenación..." op.cit., p. 392. Sobre esta primera fase de actividad hidráulica de Felipe II con Paciotto, Turriano, Herrera, Antonelli, Esquivel y Toledo, véase García Tapia, Nicolás, Ingeniería y Arquitectura en el Renacimiento español, Valladolid, Universidad de Valladolid y Caja Salamanca, 1990, pp. 552; López Gómez, Antonio et al., "Felipe II y el Tajo", en Martínez Millán, José (coord.), Felipe II (1527-1598): Europa y la Monarquía Católica. Vol. II, Madrid, Parteluz, 1998, pp. 501-526.

${ }^{40}$ Arroyo Ilera, Fernando, Agua, paisaje... op. cit., p. 31.
} 
porque en pena/haré, si en la canícula me veo, /incendio tu cristal, polvo tu arena"41 o "Rico en invierno y pobre en el estío/ parezco en mi fortuna Manzanares, / que con agua o sin ella siempre es río"42. Precisamente porque siempre es río y alabanza de la ciudad, Lope trataba de elogiarlo con conscientes exageraciones — “juncoso Manzanares, pues excedes/ del Tajo la corriente caudalosa"43 - intentando establecer una relación de superioridad ideal entre Toledo y Madrid en su rivalidad por el asiento de la corte. El poeta se hace portavoz de una parte de los procuradores en Cortes. Maldonado de Matute en su Discurso sobre la mudanza de la Corte de 1600 dice del Manzanares que es un "río bastante para lo necesario" ${ }^{44}$ pues, cubiertas las necesidades de abastecimiento hídrico con los viajes de agua, el lugar era más bien una zona de recreo. Según Pérez de Herrera, era un “[...] río, que aunque de suyo no es grande, a lo menos

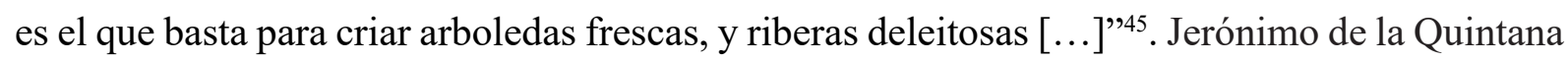
sostiene que no es caudaloso pero es apacible: “era el mejor río [...] porque se podía en coche y a caballo ir [...] sin peligro alguno, gozando de una y otra parte de amenos sotos, y verdes alamedas" ${ }^{46}$. Esta misma imagen la encontramos en La Dorotea (1632):

"Dorotea: Manzanares no se precia de profundo [...] oropel y ruido de orillas sí, y de seguridades. No es traidor como otros ríos [...] como aquel Minotauro que se comía los hombres [...] que si por el Betis vienen barcos de plata [...], por Manzanares vienen coches de perlas y diamantes $[\ldots]^{\prime 47}$.

Años más tarde Núñez de Castro afirma que Madrid tiene los divertimentos necesarios "río que la bañe, huertas que la cerquen, salidas amenas en que se desenfaden las tareas de los Cortesanos [...] Ay [sic.] río en Madrid para el recreo sin el peligro, para los divertimientos sin el riesgo" y continúa diciendo "en Madrid todos los coches y carrozas hacen de Gondolas"48.

En estas descripciones se refleja el proyecto real de hacer de esta zona un espacio de ocio y recreación ${ }^{49}$ como no pinta Lope.

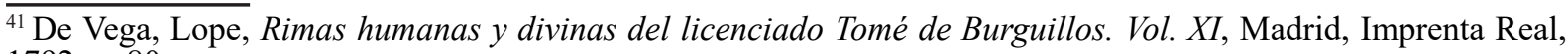
1792 , p. 80.

${ }^{42}$ Ibídem, p. 92.

${ }^{43}$ De Vega, Lope, Poesías líricas, en Fernández Montesinos, José (ed.), Madrid, Espasa-Calpe, 1968, p. 120. Fragmento del soneto VIII, publicado en Rimas humanas y divinas, 1634.

${ }^{44}$ Cfr. Cavillac, Michel, "El Madrid utópico..." op cit., p. 641.

${ }^{45}$ Pérez de Herrera, Cristóbal, Discurso a la Catolica ... op. cit., fol. 3r.

${ }^{46}$ De la Quintana, Jerónimo, A la muy antigua ... op. cit., lib. I, cap. II, fol. 2r.

${ }^{47}$ De Vega, Lope, La Dorotea, en Morby, Edwin (ed.), Valencia, Artes gráficas Soler, 1968, acto II, escena II, p. 145.

${ }^{48}$ Núñez de Castro, Alonso, Solo Madrid es Corte...op. cit. fols. 12 y 13 respectivamente.

${ }^{49}$ Véase Alvar Ezquerra, Alfredo, El nacimiento... op. cit. p. 191.
} 
3. "iQuítenme aquesta puente que me mata!"

Para este río tan poco caudaloso Felipe II mandó construir un "edificio mas sumptuoso" 50 para el río Manzanares:

\author{
Sobre quien espero ver \\ aunque en humilde corriente \\ una machina excelente \\ que de Hercules exceder \\ pueda la famosa puente ${ }^{51}$.
}

En el poema Isidro — ambientado en época del santo-, será el río Manzanares quien profetiza la construcción de este puente comparándolo con el famoso acueducto de Segovia por equiparación con el nombre. La Puente Segoviana, según Gil González Dávila "la máquina excelente", se convirtió en la entrada simbólica a la villa que había retratado Wyngaerde para el Rey. Su construcción (1584) s2 $^{52}$ coincide en fechas con la utópica idea de hacer navegable el Tajo-Jarama-Manzanares (1582), así que se realizaría con la esperanza de un río más caudaloso, como la misma personificación del Manzanares reclama a los corregidores:

\footnotetext{
¡Quítenme aquesta puente que me mata, señores regidores de la villa [...]

De bola en bola tanto se dilata [... mejor es que la lleven a Sevilla [...] Percibiendo de sed en el estío, es falsa la causal y el argumento de que en las tempestades tengo brío. Pues yo con la mitad estoy contento, tráiganle sus mercedes otro río que le sirva de huésped de aposento ${ }^{53}$.
}

\footnotetext{
${ }^{50}$ Pérez de Herrera, Cristóbal, Discurso a la Catolica... op. cit. Según apunta León Pinelo costó doscientos mil ducados, en Pinelo, León, Anales de Madrid de Leon Pinelo. Reinado de Felipe III. Años 1598 a 1621, Valladolid, Maxtor, 2003, fol. 116r.

${ }^{51}$ Vega, Lope de, Isidro. Poema castellano, Barcelona, Honofre Anglada, 1608, fol. 228r.

${ }^{52}$ Navascués Palacio, Pedro, "Puentes de acceso a El Escorial", en Archivo español de Arte, t. 58, 230 (1985), p. 97. Véase también Fernández Casado, Carlos, "Historia documentada de los puentes de Madrid", en Revista de la Biblioteca, Archivo y Museo del Ayuntamiento de Madrid, 67 (1954), pp. 65-84.

${ }^{53}$ De Vega, Lope, Rimas... op. cit., p. 93-94.
} 
Figura 2: Vista del Alcázar de Madrid, Félix Castello (1630-1640).

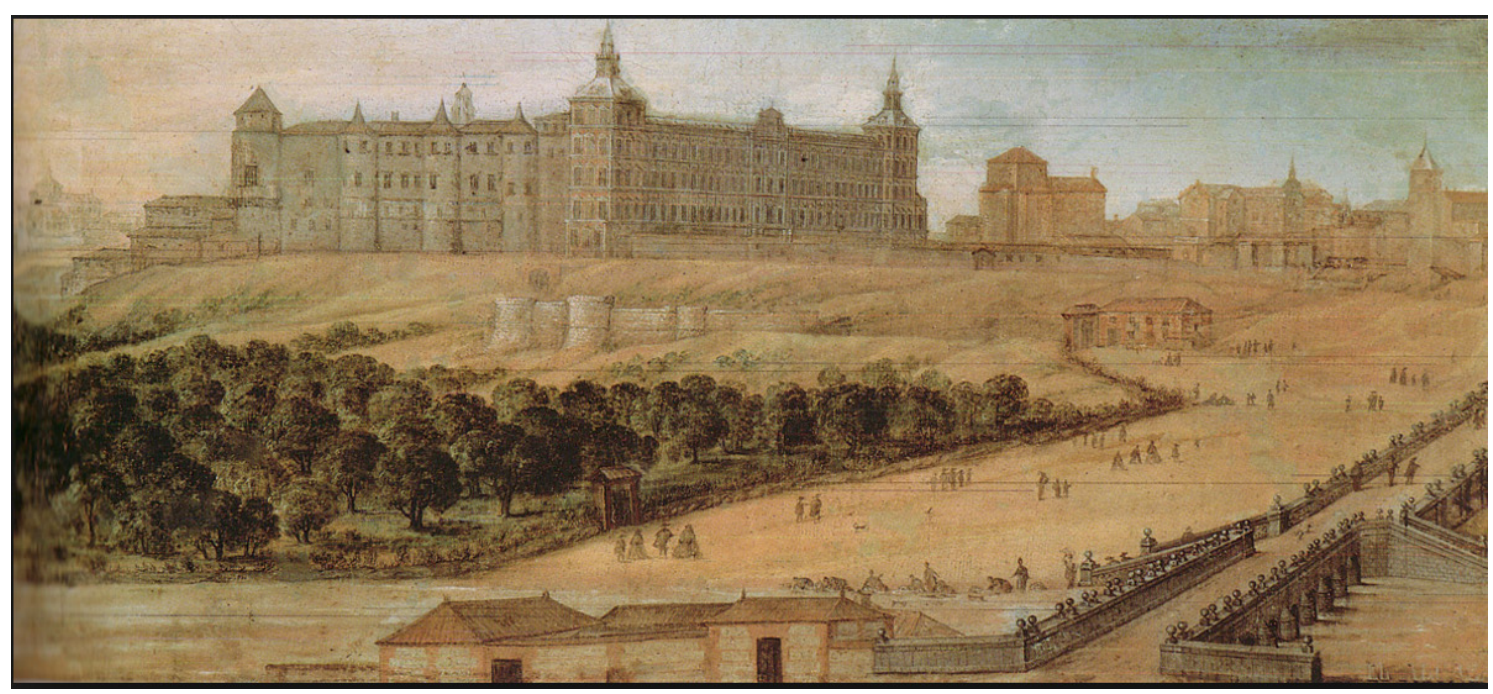

Fuente: Museo Municipal de Madrid.

El puente [fig. 2] formaba parte del programa simbólico de embellecimiento de la villa. Es recurrente en Lope la iconografía del poder en general, y en particular en ámbito urbanístico. Sus plásticas descripciones están jalonadas de elementos filípicos de tradición escurialense como obeliscos, bolas y cruces, como podemos notar en los versos anteriores, pues la decoración es lo más sobresaliente desde un punto de vista visual y sensorial, símbolos de la universalidad monárquica ${ }^{54}$. Como señala el poeta, efectivamente los arcos de medio punto debían de resultar demasiado amplios para tan poco caudal, mofándose de la fortaleza del puente contra las tempestades. Por eso, el Manzanares cede tan magnífico puente al Guadalquivir ${ }^{55}$, o sugiere traer otro río como huésped de aposento ${ }^{56}$ —alusión al proyecto de canalización-

El agua suponía también un riesgo y peligro para el hombre y las edificaciones. Las inundaciones y las consecuentes reparaciones de los daños en murallas, puertas y edificios fue un problema económico y social grave. Precisamente la ausencia de peligros era la ventaja del Manzanares, frente a ciudades como Sevilla o Valladolid que sufrían daños periódicamente.

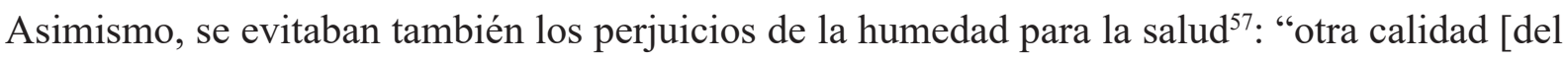

\footnotetext{
${ }^{54}$ Cfr. Rincón Álvarez, Manuel, Claves para comprender el Monasterio de San Lorenzo de el Escorial, Salamanca, Universidad de Salamanca, 2007, p. 79.

${ }^{55}$ En el siglo XVI Sevilla contaban con el Puente de las Barcas, una pasarela de madera flexible de origen árabe, por eso Lope "cede" el suntuoso puente de Segovia al Guadalquivir. Hasta el siglo XIX no se construyó el Puente de Isabel II, a pesar de la existencia de proyectos como el de Pedro de Andrade en 1585 y el de Andrés de Oviedo en 1629. Sobre la ciudad de Sevilla, véase Domínguez Ortiz, Antonio, Historia de Sevilla: la Sevilla del siglo XVII, Sevilla, Universidad de Sevilla, 1986.

${ }^{56}$ Lope reflexiona sobre los esfuerzos de la ciudad para alojar a la Corte con una sutilísima comparación, con tintes de crítica velada, entre la canalización de las aguas alojadas en el cauce del río y la regalía de aposento. Véase Molina Campuzano, Miguel, Planos de Madrid de los siglos XVII y XVIII, Madrid, Instituto de Estudios de Administración Local, 1960 , pp. 120 y siguientes.

${ }^{57}$ Sobre los daños de un enclave húmedo y los problemas de salud ya se habían pronunciado Aristóteles y Alberti, autores a los que remitieron los escritores del XVI y XVII. Frente a la imagen literaria de corte panegirista de Madrid, la realidad era muy diferente. El asentamiento de la Corte, clima, arquitectura y política estaban interrelacionados;
} 
Manzanares...] es ir y correr por parte donde es de gran servicio [...], sin poder causar ningún daño su creciente y avenidas; como [...] en otras ciudades [...], Valladolid y Sevilla, con gran estrago dellas" ${ }^{\prime 5}$.

En cuanto a la personificación del río, el tópico contaba con referencias clásicas tan importantes como el Po de Virgilio, "fluviorum rex", o el "padre Tíber". La iconografía de la personificación del río ya estaba normalizada en el mundo helenístico como un anciano barbudo y desnudo en posición yacente con la cabeza, frente o pecho levantado ${ }^{59}$. En España también fue muy explotado en el teatro ${ }^{60}$ y en la escenografía de fiestas, como en la entrada de Felipe II en Sevilla, en cuyo recorrido el primer arco junto a la muralla incluía las figuras de Hércules y el Betis como emblema de la ciudad ${ }^{61}$.

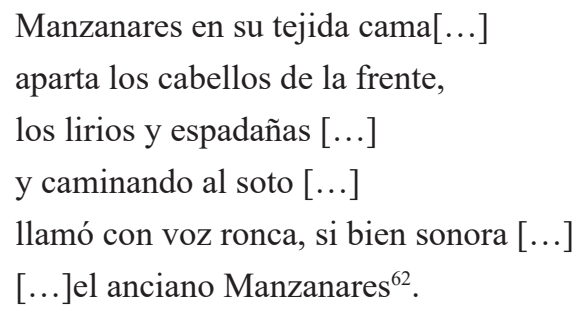

El anciano profeta Manzanares aparece también en una de las primeras personificaciones lopedeveguescas del río como instrumento de reflexión sobre el pasado histórico de la villa:

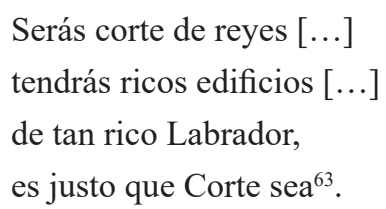

véanse los datos de los Libros de Acuerdos del Ayuntamiento de Madrid sobre aguas, fuentes y puentes en Alvar Ezquerra, Alfredo et al., "Clima, técnica y poderes. Madrid, 1561-1598", en Revista de historia moderna, 23(2005), pp. $135-184$.

${ }^{58}$ Pérez de Herrera, Cristóbal, A la Catolica y Real Magestad del Rey don Felipe III, suplicando à su Magestad, que atento las grandes partes y calidades desta villa de Madrid, se sirua de no desampararla, sino antes perpetuar en ella la assistencia de su casa y gran Monarchia, 1600, fol. 4r-4v. Teniendo en cuenta la fecha del memorial probablemente se alude a las inundaciones y crecidas del Pisuerga en enero de 1597. En cambio, Sevilla había sufrido varias inundaciones y crecidas durante el siglo XVI, algunas de las más graves entre 1593 y 1596 . Véase Ortiz de Zúñiga, Diego, Anales eclesiásticos y seculares de la muy noble y muy leal ciudad de Sevilla. Vol. IV, Madrid, Imprenta Real, 1796, pp. 156 y 161 respectivamente. Para una panorámica general, Palomo, Francisco Borja, Historia crítica de las riadas de Sevilla (1878), Sevilla, Ayuntamiento de Sevilla, 2001; y Núñez Roldán, Francisco, La vida cotidiana en la Sevilla del Siglo de Oro, Madrid, Sílex, 2004. Según este último autor, durante el siglo XVI (entre 1504 y 1596) se registran dieciséis inundaciones. Ibídem, p. 35.

${ }^{59}$ Piénsese, por ejemplo, en el Grupo del Nilo de la escuela de Alejandría o las enjutas del arco de Séptimo Severo, iconografía que después influyó en el Renacimiento y Barroco con ejemplos tan famosos como las esculturas de Miguel Ángel o la fuente de los cuatro ríos de Bernini.

${ }^{60}$ Véase García Gutiérrez, Juan, "El tópico de la personificación de un río (Presencia del mismo en la literatura latina y en la española)", en Revista de Estudios Extremeños, vol. 67, 1 (2011), pp. 35-46.

${ }^{61}$ De Mal Lara, Juan, Recibimiento que hizo la muy Noble y Muy Leal Ciudad de Sevilla a la C.R.M. del Rey don Phelipe N.S. va todo figurado con una Breve Descripción de la Ciudad y su tierra, Sevilla, Juan de Escribano, 1570; Rodríguez, Gaspar, Relación muy verdadera del feliz recibimiento que al invencible y serenísimo Rey Don Phelipe nuestro Señor, se hizo en la muy noble y muy leal ciudad de Sevilla, Sevilla, 1570. Cfr. Lleó Cañal, Vicente, Nueva Roma. Mitología y humanismo en el Renacimiento sevillano, Sevilla, Diputación Provincial de Sevilla, 1979, pp. 173 y ss.

${ }_{62}$ De Vega, Lope, El laurel de Apolo... op. cit., pp. 89-91.

${ }^{63}$ De Vega, Lope, Isidro... op. cit., fol. 184r. 
En esa relectura histórica, Lope otorga un papel determinante a San Isidro ${ }^{64}$. Y una vez más el río profetiza, dentro de esa visión providencialista de la historia, que Madrid será Corte:

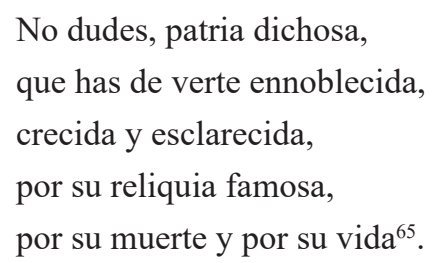

El río, emblema de la ciudad, testigo del tiempo y de la historia, está asociado a la villa como ningún otro elemento simbólico autoidentificado con su territorio ${ }^{66}$, pero los panegiristas tuvieron que centrar sus alabanzas en las riberas, más que en el caudal, convirtiéndose en enigma retórico de la propia villa, pues "tiene río, y no tiene río" ${ }^{67}$, pero "que con agua o sin ella siempre es río" ${ }^{\circ 8}$.

Figura 3: Detalle del Plano de Texeira (1656).

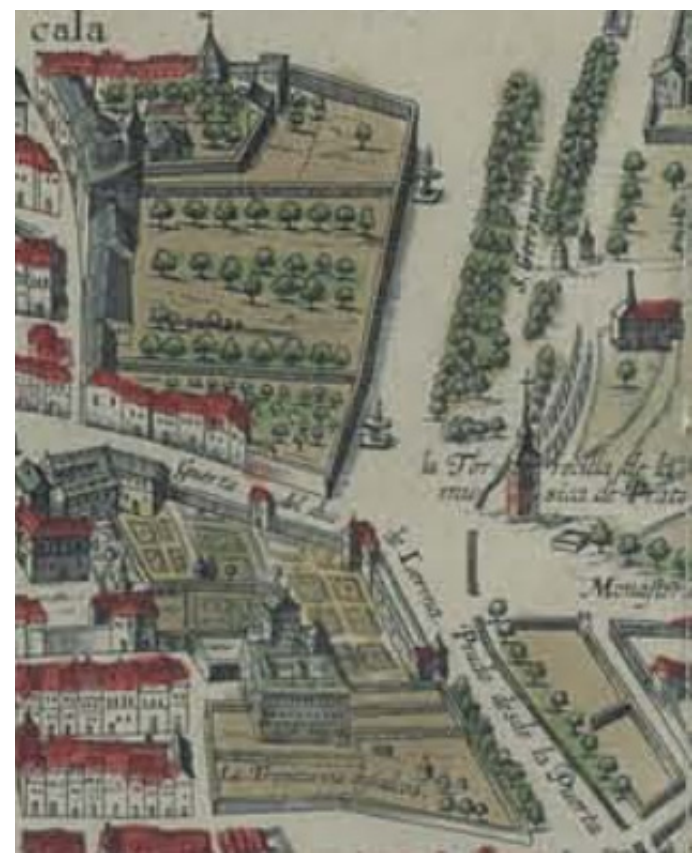

Fuente: Biblioteca Nacional de España, Invent/23233.

\footnotetext{
${ }^{64}$ En el pasado glorioso de Toledo, también el Tajo desempeñó un papel profético con Rodrigo y la lucha contra los árabes, véase García Gutiérrez, Juan, "El tópico..." op. cit., p. 37.

${ }^{65}$ De Vega, Lope, Isidro... op. cit., fol. 183v. En este caso, la nobleza de la villa se debe a la reliquia de los restos y al propio santo.

${ }^{66}$ Cfr. Arroyo Ilera, Fernando, Agua, paisaje... op. cit., pp. 23 y ss.

${ }^{67}$ De Vega, Lope, Mudanzas de Fortuna y sucesos de Don Beltrán de Aragón, edición digital a partir de Tercera parte de las comedias de Lope de Vega y otros autores, Madrid, Miguel Serrano de Vargas, 1613, acto II, fol. 135v. ${ }^{68}$ De Vega, Lope, Rimas...op. cit., p. 92.
} 
4. "Traila del Caño Dorado"

La búsqueda de pozos de agua fue una obsesión constante desde el establecimiento de la Corte en Madrid $^{69}$. De este modo, los manantiales de agua y las fuentes llegaron a convertirse en "un hito esencial del territorio"

Gil González Dávila menciona 22 fuentes en la villa de Madrid con sus pesos ${ }^{71}$, mientras que Jerónimo de la Quintana menciona solo las dieciséis fuentes más antiguas "para que no se pierda la memoria dellas" "72. En las descripciones destaca la novedad del artificio y era habitual que las gentes salieran a contemplarlas: "Vamos a ver estas fuentes/ si cansada no te sientes"73.

Lope describe la belleza que generaba esa superposición artificial a la naturaleza:

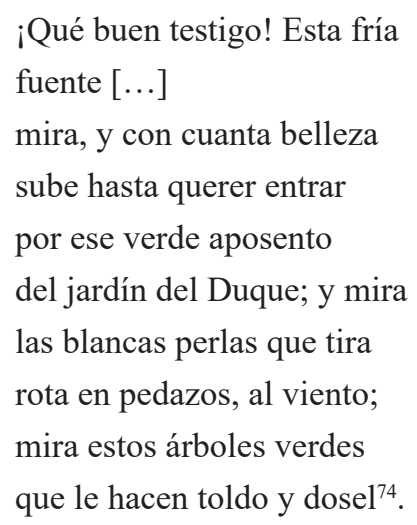

Se describe aquí el cruce entre la Carrera de San Jerónimo y el Prado ${ }^{75}$, en cuya esquina estaba la Huerta del Duque de Lerma ${ }^{76}$, y la fuente como "naturaleza artificiosa" o "artificio

\footnotetext{
${ }^{69}$ En 1562 Felipe II manda elevar el Memorial de las aguas que se han hallado en el Prado, Archivo General de Simancas, Casa y Sitios Reales, leg. 247, fol. 46.

${ }^{70}$ Arroyo Ilera, Fernando, "La imagen del agua..." op. cit., p. 167.

${ }^{71}$ González Dávila, Gil, Teatro de las... op. cit., lib. I, fols. 7-8. Para las fuentes de Madrid y el modo de pesar las aguas, véase Guerra Chavarino, Emilio, Los viajes de agua y las fuentes de Madrid. Los viages-qanat, Madrid, La Librería, 2011.

${ }^{72}$ De la Quintana, Jerónimo, A la muy antigua... op. cit., lib. I, cap. II, fols. 3r-3v. En el Plano de Texeira, en cambio, aparecen representadas en el recinto de Madrid unas 200 fuentes, véase Gea Ortigas, María Isabel, Guía del plano de Texeira (1656), Madrid, La Librería, 2006. Sobre las fuentes de Madrid, véase Martínez Carbajo Agustín y Pedro García Gutiérrez, Fuentes de Madrid, Madrid, La Librería, 2009.

${ }_{73}$ De Vega, Lope, El Acero... op. cit., p. 225.

${ }^{74}$ Ibídem, p. 138.

${ }^{75}$ Véase Lopezosa Aparicio, Concepción, Origen y desarrollo de un eje periférico de la capital, Paseo de Agustinos Recoletos, Paseo del Prado Viejo de San Jerónimo y Paseo de Atocha, tesis doctoral, Universidad Complutense de Madrid, 2003.

${ }^{76}$ Véase Porras Pasamontes, Carmen, "La huerta del Duque de Lerma en el Paseo del Prado", en Madrid histórico, 10 (2007), pp. 16-17; Lopezosa Aparicio, Concepción, "La residencia del Duque de Lerma en el Prado de San Jerónimo, traza de Gómez de Mora", en Revista de arte, geografía e historia, 1 (1998), pp. 457-486.
} 
natural" 77 que pretendía "naturalizar la ciudad" o "urbanizar el campo"78. Las fuentes como ningún otro elemento suponen la supremacía del arte y la técnica sobre la Naturaleza ${ }^{79}, y$ junto con las huertas y las casas de recreación en los alrededores de la ciudad, permitían un contacto culto y humanista con la naturaleza.

Felipe II mandó acondicionar el Prado de San Jerónimo que, antes de 1561, ya era uno de los mayores atractivos del lugar como afirma Pedro de Medina, con árboles y fuentes que debían ser abastecidas por un nuevo viaje de agua, el del Abroñigal Bajo ${ }^{80}$. Había frente al Caño Dorado junto a la Torrecilla de la Música ${ }^{81}$, otra fuente de cinco caños cuyas aguas intentan subir "por ese verde aposento/ del jardín del Duque" [fig. 3]. En El Acero de Madrid (1608) $)^{82}$ Lope describe probablemente la fuente situada frente a la Huerta descrita por López de Hoyos y que sirvió de modelo para las fuentes del Prado de San Jerónimo diseñadas por el maestro Juan Díez y ejecutas por el cantero Juan de Solano Palacios en 1615:

"A la mano derecha de la entrada del Prado da luego la vista en una fuente,
de enmedio de la cual salen cinco caños, que suben los cuatro tres pies en
alto, y al caer hacen cuatro arcos, que resuenan en el borde de la bacía harto e
graciosamente. De enmedio sale otro, que sube más que ninguno"s3.

Precisamente la supeditación del curso natural del agua invirtiéndolo hacia arriba era una novedad técnica sorprendente, "causando maravilla a los que ven el altura a que sube el agua dellas" ${ }^{\prime 4}$. En las descripciones literarias no solo destaca el frescor que procuraban las fuentes, sino también del sonido, de la musicalidad del agua:

\footnotetext{
${ }_{77}$ Checa Cremades, Fernando y José Miguel Morán Turina, El Barroco, Madrid, Istmo, 2001, pp. 125-130. Cervantes habla incluso de una "terzia naturaleza" formada por "la naturaleza, encorporada con el Arte, es hecha Artifice i connatural del Arte", en de Cervantes, Miguel, La Galatea dividida en seis libros, Madrid, Juan de Zúñiga, 1736, p. 267.

${ }^{78}$ Checa Cremades, Fernando, "El estilo clásico", en Nieto, Víctor et al. (coords.), Arquitectura del Renacimiento en España 1488-1599, Madrid, Cátedra, 1993, p. 286.

${ }^{79}$ Véase Orozco Díaz, Emilio, "Ruinas y jardines. Su significación y valor en la temática del Barroco", en Orozco Díaz, Emilio, Temas del Barroco en poesía y pintura, Granada, Universidad, 1989.

${ }^{80}$ Véase Pinto Crespo, Virgilio et al., Los viajes de agua de Madrid durante el Antiguo Régimen, Madrid, Fundación Canal, 2010.

${ }^{81}$ Morán Turina, Miguel y Bernardo García García, El Madrid de Velázquez y Calderón. Villa y Corte en el siglo XVII, Madrid, Ayuntamiento de Madrid y Fundación Caja Madrid, 2000. Aparece en el plano con el número 67. Téngase en cuenta que aquí tocaban músicos también para deleite de los madrileños. Véase Lopezosa Aparicio, Concepción, "Un singular edificio del Prado Viejo de San Jerónimo: la Torrecilla de Música", en Anales de historia del arte, 5 (1995), pp. 93-100; García Herrero, Miguel, "Las fuentes de Madrid: reformas de Felipe III", en Revista de la Biblioteca, Archivo y Museo, 28 (1930), pp. 373-388. Para las descripciones anteriores al mapa de Texeira, véase López de Hoyos, Juan, Real apparato.. op. cit.

${ }^{82}$ Para la datación de la obra, Arata, Stefano, "Proyección escenográfica de la huerta del duque de Lerma en Madrid”, en Civil, Pierre (coord.), Siglos dorados. Homenaje a Agustín Redondo, Madrid, Castalia, 2004, pp. 33$52 .$.

${ }^{83}$ López de Hoyos, Juan, Real aparato... op. cit., fols. 7r-8v.

${ }^{84}$ De la Quintana, Jerónimo, A la muy antigua ... op. cit., lib. I, cap. II, fol. 3r. Para las descripciones de El Prado por los viajeros extranjeros, véase Checa Cremades, José Luis, Madrid en la prosa de viaje I (siglos XV, XVI y XVII), Madrid, Comunidad de Madrid, 1992; y García Mercadal, José, Viajes de extranjeros por España y Portugal, Salamanca, Junta de Castilla y León, 1999.
} 
Baramo: Ay tal aire.

Felisardo: Ay tal correr

de siempre músicas fuentes.

Felisardo: Pues no dudéis, que alabando

a Dios, salen de sus venas,

$\mathrm{y}$ van por estas arenas

eternos versos cantando ${ }^{85}$.

Muchas de ellas eran de aguas muy saludables. Las mejores y más delgadas

serían las de la Fuente Castellana, la Puente Segoviana o Humilladero, el Caño

Dorado y Leganitos ${ }^{86}$, cualidades que también Lope menciona:

Feliciano: Traila del Caño dorado.

Aurel: iQué linda agua!

Faustino: No ha salido

de la tierra cosa igual

Feliciano: Mejor la de Leganitos

que esto dicen infinitos

Faustino: Si lo dicen, dicen mal

que está pesada con ella

y basta que sean iguales ${ }^{87}$.

La fuente del Caño Dorado se encontraba en medio del Prado de San Jerónimo, mientras que la de Leganitos en el camino a San Bernardino ${ }^{88}$. Estas dos fuentes debían tener "agua dulcissima, limpia, delgada y muy sana [...] como son las de Lavapiés [...y] Leganitos que [...] son extremadas de buenas"89. Según Gil González Dávila, la del Caño Dorado pesaba dos libras, cinco onzas, siete adarmes y 13 gramos, mientras que la de Leganitos pesaba dos libras, cinco onzas, siete adarmes y 16 gramos $^{90}$, mientras que Lope sostiene que tenían el mismo peso.

Entre las propiedades benéficas, las aguas de Madrid eran capaces de curar el mal de piedras y de riñón ${ }^{91}$ y había además dos fuentes santas: la del Convento de Santo Domingo y la de San Isidro ${ }^{92}$.

\footnotetext{
85De Vega, Lope, Los amantes sin amor, edición digital a partir de Parte catorze de las comedias de Lope Felix de Vega Carpio, Madrid, Juan de la Cuesta, 1620, acto III, fol. 18; o también: “Al son de los arroyuelos/ [...] al son de arroyos sonoros/ cantan las aves a coros, [ [... Suenan del agua las venas,/ instrumento natural [...]", en de Vega, Lope, La Dorotea... Añadidos a esta impresión El arte Nuevo de hacer comedias, un catálogo de las obras que este autor escribió, y otro de varios libros de diversión, Madrid, Librero de Cámara de su Magestad, 1736, acto II, fols. $60 \mathrm{r}-61 \mathrm{v}$.

${ }^{86}$ González Dávila, Gil, Teatro de las...op. cit., lib. I, cap. III, fol. 7.

${ }^{87} \mathrm{De}$ Vega, Lope, El desposorio encubierto, edición digital a partir de Trezena parte de las comedias de Lope de Vega Carpio, Madrid, viuda de Alonso Martín, 1620, acto II, fol. 118r-119v. La fecha de redacción se sitúa entre 1597 y 1603.

${ }^{88}$ González Dávila, Gil, Teatro de las...op. cit., lib. I, cap. III, fol. 7.

${ }^{89}$ De Pereda,Francisco, Libro Intitulado la Patrona de Madrid y venida de Nuestra Señora a España, Valladolid, 1604, lib. I, cap. I, fols. 2r-3v.

${ }^{90}$ González Dávila, Gil, Teatro de las...op. cit., lib. I, cap. III, fol. 7.

${ }^{91}$ De la Quintana, Jerónimo, A la muy antigua ... op. cit., lib. I, cap. II, fol. 3r.

${ }^{92}$ González Dávila, Gil, Teatro de las...op. cit., lib. I, cap. III, fol. 8.
} 
5. "San Isidro, un nuevo Moisés pareces"

Núñez de Castro, a diferencia de sus predecesores, atribuye la fecundidad del suelo al cielo de Madrid: "Yo no admiro sus fecundidades [del suelo] habiéndose debido los surcos al afán de los Ángeles, sustitutos del venturoso Labrador Isidro [...] los Cortesanos del Cielo, se preciaron en nuestra Corte de labradores, calificando de Cielo el terruño de Madrid" ${ }^{93}$.

Madrid, "fundada sobre agua", había de tener como patrón un santo pocero y, una vez asentada la Corte en Madrid, el ayuntamiento y Felipe II impulsaron la iniciativa. Domingo de Mendoza le encargaría la biografía a Lope de Vega ${ }^{94}$. Por las cartas de ambos, fue en el verano de 1596 cuando Mendoza le pidió que escribiera la historia del Santo. En una carta de Mendoza a Lope dice: "Cuando vi a V. m. este verano pasado [...] me hizo merced de darme su palabra de escribir muy de su mano la historia, grandezas y milagros deste esclarecido santo"95. Para ello le manda documentación, papeles "todos ellos verdaderos y fidedignos" aunque "cosas hay, que los que nacimos en esta villana sabemos en naciendo, sin que nadie nos las enseñe, y diga" ${ }^{96}$ y se denomina el cronista de la historia: "[...] mas nací/ en vuestro mesmo lugar,/ [...] y así de fama y de vista/ soy vuestro coronista" ${ }^{" 97}$. El poeta fue el encargado de escribir varias obras sobre el santo, además de la crónica de los festejos ${ }^{98}$, ocupando un papel destacado en el proceso de beatificación en $1620^{99}$ y canonización en Roma ${ }^{100}$ dos años más tarde con fiestas notables.

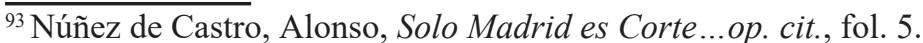

${ }^{94}$ Cfr. Fernández Montes, Matilde, "San Isidro..." op. cit., p. 68.

${ }^{95}$ De Vega, Lope, Isidro... op. cit., prólogo, sf.

${ }^{96}$ Ibídem, prólogo, sf. Del Río Barredo sostiene que nunca le pasó los documentos a Lope, aunque la correspondencia entre ellos parece indicar lo contrario. Cfr. Del Río Barredo, María José, "Literatura y ritual en la creación de una identidad urbana: Isidro, patrón de Madrid", en Edad de oro, 17 (1998), p. 154.

${ }^{97}$ De Vega Lope, Isidro...op. cit., fol. 78r. Para las aspiraciones de Lope y el puesto de cronista, véase Bershas, Henry, "Lope de Vega and the Post of Royal Chronicler", en Hispanic Review, vol. 31, 2 (1963), pp. 109-117. DOI: https://doi.org/10.2307/471361; y Wright, Elizabeth, Pilgrimage to Patronage: Lope de Vega and the Court of Philip III, 1598-1621, Lewisburg, Bucknell University Press, 2001. DOI: https://doi.org/10.2307/471361.

${ }^{98}$ En 1599 publica Isidro Poema Castellano. En 1617 publica la comedia San Isidro Labrador de Madrid en la Séptima parte, y con motivo de la canonización en 1622 publica otras dos comedias La niñez y La juventud de San Isidro, y sus respectivas loas, formando parte de la Relación de las fiestas que la insigne villa de Madrid hizo en la canonización de su bienaventurado hijo y patrón San Isidro, con las dos comedias que se representaron y los versos que en la Justa poética se escribieron. Estas dos comedias fueron representadas al aire libre en la plaza de Palacio. Se le encargan además las respectivas relaciones de las fiestas: Justa poética, y alabanzas justas que hizo la insigne villa de Madrid al bienaventurado San Isidro en las fiestas de su beatificación, recopiladas por Lope de Vega. Dirigidas a la misma insignevilla (1620) y Relación de las fiestas... op. cit. (1622).

${ }^{99}$ Para la reconstrucción del proceso de beatificación remitimos al lector a Zozaya Montes, Leonor, "Pesquisas documentales para narrar la historia de San Isidro. Gestiones para una canonización iniciada en 1562", en Prisma Social, 4 (2010), pp.1-35. «http://www.isdfundacion.org/publicaciones/revista/pdf/01_N4 PrismaSocial_ leonorlars.pdf» [consultado el 30 de noviembre de 2017]; Rodríguez Pedraza, Gema, "Sañ Isidro Labrador $\bar{y}$ su esposa Santa María de la Cabeza, Mariano Salvador Maella", en «http://eu.museoromanticismo.mcu.es/web/ archivos/documentos/mayo_san_isidro.pdf» [consultado el 30 de noviembre de 2017]; del Río Barredo, María José, "San Isidro y la crónica de una capital incierta”, en del Río Barredo, María José, Madrid, urbs regia... op. cit., pp. 94-118; Guerra Chavarino, Emilio, "Leyenda e Historia de San Isidro Labrador y de Santa María de la Cabeza" en La Gatera de la Villa, 19 (2015), pp. 44-51.

${ }^{100}$ Lope de Vega menciona a Mendoza como artífice: "Era Canonización [...]/ Cuya execución emprende/ Fray Domingo de Mendoza", en de Vega, Lope, Isidro... op. cit., canto X, fol. 252r. Sobre quién tomó la iniciativa o jugó un papel de primera importancia en el proceso se proponen diferentes nombres, véase León Pinelo, Antonio,
} 
El santo, con su iconografía clásica de "aguijada de plata", perfora la tierra para hacer brotar las ricas aguas del subsuelo de Madrid, "porque el gobierno/ de los campos es agua"101, y está asociado, sin duda, a la tradición islámica de los viajes de agua ${ }^{102}$. Entre los milagros hidráulicos mencionados por Lope en diferentes obras sobre el Labrador, destaca el milagro de la fuente en el que San Isidro como Moisés:

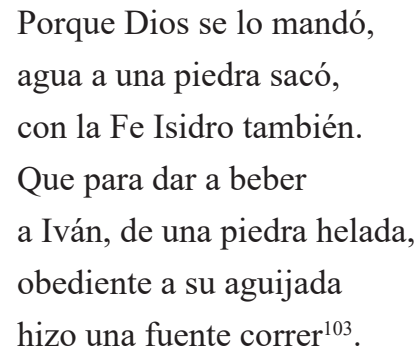

La fuente de San Isidro (siglo XII), situada en el actual cementerio de San Isidro, fue un lugar de culto del Santo muy importante por sus aguas milagrosas ${ }^{104}$. Allí se erigió la Ermita de San Isidro entre 1528 y $1537^{105}$ y el Consejo Real ayudó a costear los arreglos de la misma en 1568 y posteriormente en $1594^{106}$.

Con el eminente respaldo de Plinio y sus alabanzas a las aguas medicinales de la Carpetania ${ }^{107}$, dentro de una tradición de santos y santas protectores de la salud de la monarquía, las aguas milagrosas de San Isidro adquirieron notable fama, sanando incluso a Carlos I y Felipe II de calenturas ${ }^{108}$ :

Anales... op. cit.; de la Cruz, Nicolás Joseph, Vida de San Isidro Labrador, patrón de Madrid, adjunta la de su esposa Santa María de la Cabeza, Madrid, Imprenta Real, 1790, pp. 173-179, en especial p. 174 (ed. facsímil en Recuerdos de la Villa de Madrid: vida de San Isidro Labrador, Madrid, Marco Real Editor, 1986, tomo III); García Villada, Zacarías, San Isidro Labrador en la historia y en la literatura, Madrid, Razón y Fe, 1922, pp. 95 y ss.; Fernández Montes, Matilde, "San Isidro, de labrador medieval a patrón renacentista y barroco de la villa y Corte", en Revista de Dialectología y Tradiciones Populares, vol. 4, 1 (2001), p. 66. Para un estudio más profundizado sobre el proceso y los participantes en él, véase Zozaya Montes, Leonor, "Pesquisas documentales..." op. cit.

${ }^{101}$ Vega, Lope de, La niñez de San Isidro, en Relación de las fiestas ... op. cit., acto I, fol. 7r.

${ }^{102}$ Véase Zozaya Montes, Leonor, "Construcciones para una canonización: reflexiones sobre los lugares de memoria y de culto en honor a San Isidro Labrador", en Tiempos Modernos: Revista electrónica de Historia Moderna, vol. 7, 22 (2011). «http://www.tiemposmodernos.org/tm3/index.php/tm/article/view/260» [consultado el 30 de noviembre de 2017].

${ }^{103}$ De Vega, Lope, La juventud de San Isidro, en Relación de las fiestas... op. cit., acto II, fol. 32r. Y de nuevo: "Un nuevo Moisés pareces/ Válgame el cielo, qué es esto?/ Es su vara tu aguijada./ Que una seca peña helada/ te ha obedecido tan presto?/ Con las manos de Dios llenas/ has hecho aquesta sangría/ porque solo Dios podía/ hallar el agua en sus venas" en Vega, Lope de, San Isidro Labrador, en Septima parte de sus comedias: con loas, entremeses y bayles, Madrid, viuda de Alonso Martín, 1617, acto III, fol. 279r.

${ }^{104}$ González Dávila, Gil, Teatro de las...op. cit., lib. I, cap. III, fol. 8.

${ }^{105}$ Verdú Ruiz, Matilde, "La Rivera del Manzanares", en VV. AA., Establecimientos tradicionales madrileños. Cuaderno VII. El ensanche Sur y la Ribera del Manzanares, Madrid, Cámara de Comercio e Industria de Madrid, 1986 , pp. 52-53.

${ }^{106}$ Zozaya Montes, Leonor, "Construcciones para una..." op. cit.

${ }^{107}$ Cfr. de Morales, Ambrosio, Las Antiguedades de las ciudades de España que se nombran en esta Coronica con un discurso al principio de las maneras que puede aver para averiguar y entender el verdadero sitio y nombre, que antiguamente tuvieron, Alcalá de Henares, Imprenta de Juan Íñiguez de Lequerica, 1577, n. 3, fol. 95r.

${ }^{108}$ Sobre el tema véase Landa Goñi, Jacinta, El agua en la higiene del Madrid de los Austrias, Madrid, Canal de Isabel II, 1986 
dura la fuente, a quien debe

Madrid salud celestial $[\ldots]$

que como es fuente de Fe

no puede faltarle Dios ${ }^{109}$.

Núñez de Castro resume así la importancia milagrosa del clima de Madrid para la salud:

"La parte del Cielo que le toca a Madrid en lo agradable, en lo sereno, en lo bien acondicionado de sus influjos la benignidad saludable del Cielo, corrige, embarga y purifica [...] tienen fuerza milagrosa sus aires no solo para dar vida, sino para restaurar la que se perdió. Conque en el Cielo, en tierra, en agua, en aires, se ve Madrid sin emulación victorioso" $" 110$.

\section{Conclusiones}

La importancia del agua como recurso para el abastecimiento de la villa y los problemas relacionados con la salud, la policía y el ornato del enclave urbano madrileño son evidentes por la trascendencia y calado que tuvieron en la poesía y el teatro, el medio de difusión de ideas más importante de la época. Mediante el análisis comparado de los fragmentos lopescos, hemos podido constatar, en primer lugar, que el poeta introducía con frecuencia alabanzas a las buenas cualidades de las aguas en un momento en el que la villa se debatía como sede estable de la corte frente a otras ciudades, pues precisamente las obras lopescas citadas datan de entre 1599 y 1623 en su mayoría. En segundo lugar, Lope recurría a las mismas ideas del círculo humanista madrileño heredero de la escuela de Anglería. De este modo, Lope exhibe sus conocimientos y da difusión trasversal a estas ideas, contribuyendo a la cristalización y (re)construcción de la historia local colectiva que se llevó a cabo mediante la repetición de los mismos clichés.

La antigüedad de la villa se exalta mediante el mito fundacional y la personificación del río. Por otro lado, las bondades de los viajes de agua de tradición árabe, y la búsqueda de fuentes en el subsuelo, filtrándose en el mito fundacional, en los primeros emblemas de la villa y en la propia elección de un santo pocero como patrón, reflejan la preocupación por la policía urbana y la salud, y la asimilación de la tradición islámica adaptada al cristianismo humanista. Por otra parte, el ornato de los lugares de ocio y recreo con fuentes barrocas y novedosos juegos de aguas, es indicativo del deleite del agua y la naturaleza.

\footnotetext{
${ }^{109}$ Citado en Martínez Martín, Alejo, Madrid en la poesía, Madrid, Comunidad de Madrid, 1996, p. 78.

${ }^{110}$ Núñez de Castro, Alonso, Solo Madrid es Corte... op. cit., fol. 5.
} 
Asimismo, las laudes esconden y reflejan a su vez las carencias de la villa recogidas en memoriales y descripciones de la época. La ambivalencia entre realidad e idealidad se refleja en la imagen del Madrid de Lope, una villa que oscila entre los problemas del sitio, del río o de la policía urbana, y las aspiraciones a asiento estable de Corte. La imagen literaria tuvo que "compensar" estas deficiencias con una elaborada imagen ideal. En este sentido la manipulación retórica convirtió, por ejemplo, un río poco caudaloso en un agradable y seguro paseo natural. $\mathrm{Y}$ en ese proceso de idealización de la villa, Lope contribuyó de manera decisiva y se hizo eco de las transformaciones de la urbe en relación con la Corte, por ejemplo, en la exaltación recurrente, en sus obras, del eje de expansión hacia El Prado.

Una cuarta conclusión importante que podemos colegir de la introducción y mímesis de todas estas notas corográficas está relacionada con su ambición fracasada por convertirse en cronista. La evidente aportación lopesca a la difusión de las laudes de la villa y en defensa del asiento estable de la Corte permite identificar en Lope, si bien de manera oficiosa, una función de cronista local. El papel de "cronista" que él mismo adopta para sí en relación a San Isidro, va más allá en este caso de una mera difusión de datos y teorías compartidas, poniendo su pluma al servicio de la Villa, aunque aquí se haya delineado de manera sucinta. Todos estos elementos corográficos contribuyeron, en fin, a la cristalización de una identidad colectiva local, proceso mucho más eficaz a través del teatro y la fiesta pública, en línea con ese "urbanismo de teatro" que seleccionaba lo mejor y escondía lo peor de lo que ofrecía la ciudad. 